\title{
A produção textual em contextos do letramento e significação social ${ }^{1}$
}

\author{
Adriana Cavalcanti dos Santos ${ }^{2}$ \\ Wilton Petrus dos Santos 3 \\ Nádson Araújo dos Santos ${ }^{4}$
}

\section{Resumo}

Neste artigo temos por objetivo apresentar reflexões sobre a produção escrita como prática de letramento e significações sociais. São abordadas as noções de gêneros discursivos apontando para a importância dessa materialidade em diversos contextos sociais, contemplando as concepções de multiletramento e multimodalidade dos gêneros textuais digitais na cibercultura. Traremos uma análise sobre uma atividade de produção textual a partir do gênero publicidade. Os resultados mostram que os discentes conseguiram articular oralidade, escrita e estratégias de persuasão, contextualizando-as ao seu próprio mundo, com marcas de referência ao uso das tecnologias digitais da informação e comunicação (TDIC) em suas produções, ampliando competências das organizações linguísticas e relacionando-as à produção de sentidos do texto.

Palavras-chave: Letramentos; Produção Textual; Significação Social.

\section{Textual production in contexts of literacy and social meaning}

\section{Abstract}

In this article we have for objetive to present reflections on written production as a practice of literacy and social meanings. The notions of discursive genres are addressed, pointing to the importance of this materiality in various social contexts, contemplating the concepts of multiliteration and multimodality of digital textual genres in cyberculture. We will do an analysis about a textual production activity from the advertising genre. The results show that the students were able to articulate orality, writing and persuasion strategies, contextualizing them to their own world, with reference marks to the use of digital information and communication technologies (TDIC) in their productions, expanding the competences of organizations linguistic and social and relating them to the production of meanings of the text.

Keywords: Letters; Text production; Social significance.

\section{Introdução}

Em se tratando de estudos discursivos em linguística aplicada (MOITA LOPES, 2006) nos parece razoável dizer que apontaremos para dois eixos centrais: linguagem e sociedade. Para Pennnycook (1998), as sociedades estão em níveis de completa desigualdade dominadas por

\footnotetext{
${ }^{1}$ Pesquisa realizada com apoio da Fundação de Amparo à Pesquisa do Estado de Alagoas (FAPEAL)

2 Universidade Federal de Alagoas (UFAL), Maceió, adricavalcanty@hotmail.com

${ }^{3}$ Universidade Federal de Alagoas (UFAL), Maceió, wiltonpetrus@yahoo.com.br

${ }^{4}$ Universidade Federal de Alagoas (UFAL), Maceió, nadson.araujo@gmail.com
} 
culturas hegemônicas que limitam as reflexões sobre o mundo, impossibilitando mudanças. Para o autor, o ensino e aprendizagem de língua estão ligados à manutenção dessas desigualdades como também as possibilidades de "mudá-las". Desse modo, "é dever da linguística aplicada examinar a base ideológica do conhecimento que produzimos" (PENNYCOOK, 1998, p. 22).

É de fundamental importância discutir acerca das problemáticas existentes no ambiente escolar sobre a natureza e complexidade de se ensinar a língua materna na escola. Ainda hoje, podemos perceber que existe uma linha abissal distanciando a escola das práticas concretas de uso da língua (VOLÓCHINOV, 2017) e, de forma alguma, podemos negar que estamos situados em um mundo repleto de valores políticos, históricos e desejos pessoais, que constituem significados contextualizados sobre os quais agimos como sujeitos ativos (BAKHTIN, 2011).

Ao pensarmos as práticas de ensino e aprendizagem da língua materna como prática social (VOLÓCHINOV, 2017) na escola, um conceito que merece reflexão se refere ao ensino "omnilateral" que advém de um pensamento marxista. Por sua vez, o pensamento marxista defende que o homem deve se sentir completo a partir de sua convivência em sociedade. Sendo assim, qual seria a perspectiva marxista para o trabalho escolar? "Talvez a chave para bem entender o pensamento de Marx esteja justamente aqui, no fato de que une, com austero rigor, a estrutura da escola à necessidade social de reproduzir a vida" (MANACORDA, 2007, p.108).

O processo de ensino em uma sociedade que leva seus atores a participação crítica, exigirá o conhecimento de mundo desses sujeitos. Sobre isso, lembramos que, segundo Freire (1989, p.11): “A leitura do mundo precede a leitura da palavra. Linguagem e realidade se prendem dinamicamente", de modo que texto e contexto se relacionam intrinsicamente. Narra o autor que no seu processo de alfabetização, no chão do quintal da sua casa, à sombra das mangueiras, a leitura da palavra estava colada ao seu mundo de tal forma que a leitura da palavra acabava sendo uma leitura da "palavramundo". Não se trata, então, apenas de pronunciar a palavra. Trata-se de pronunciar o mundo, ou seja, um mundo de realidades concretas. Uma leitura mais crítica do mundo e da palavra se faz necessária para formação dos sujeitos que constroem uma visão de mundo e que pode, a partir dessa visão, não apenas vê-lo, mas compreendê-lo melhor.

Mediante o contexto, neste artigo, objetivamos apresentar reflexões sobre a produção escrita como prática de letramento (ROJO, 2009) e suas significações sociais (VOLÓCHINOV, 
2017) concebendo, assim, o aprendizado não por meio de formas abstratas de unidades da língua, mas através do ato social do dialogismo (BAKHTIN, 2011). O corpus dessa análise foi coletado na ocasião de práticas de produção textual de alunos no âmbito do PIBID-LetrasPortuguês-CAPES, ocorrida no início do ano letivo de 2018. A referida intervenção, deu-se por meio de uma proposta de trabalho com os gêneros do discurso (BAKHTIN, 2011) da esfera publicitária. A produção com o referido gênero se apoiou em uma proposta do livro didático adotado pela escola e recomendado pelo Programa Nacional do Livro e do Material Didático (PNLD) para os anos de 2017-2019 (BORGATTO, 2015).

Nos tópicos a seguir, traremos uma discussão sobre letramento (ROJO, 2009) com base nos gêneros do discurso (BAKHTIN, 2011). Posteriormente, abordaremos os conceitos de texto com o aporte teórico de Volóchinov (2017); Marcuschi (2008); Koch (2015); Antunes (2005) dentre outros. Na continuidade do texto, apresentaremos o contexto metodológico deste trabalho e, traremos os dados analisados que embasam a conclusão desta pesquisa. Em últimas palavras, teceremos nossas considerações finais.

\section{Gêneros do discurso e letramentos}

Buscamos embasar nossa discussão sobre práticas de letramento(s) por intermédio de uma visão ideológica (PENNYCOOK, 1998). Deste modo, observamos as práticas de letramento(s) como indissoluvelmente ligadas às estruturas culturais e de poder da sociedade, reconhecendo assim, a variedade de práticas culturais, associados à leitura e à escrita em diferentes contextos sociais (STREET, 1993).

Para Rojo (2009), um dos objetivos da escola é possibilitar que os alunos participem de práticas sociais a partir da leitura e da escrita, o que entendemos por letramento. Mas para tal, a escola precisa levar em conta de maneira ética e democrática (PENNYCOOK, 1998) os seguintes fatores: os multiletramentos, a multimodalidade e letramento digital, deixando de ignorar os letramentos culturais locais; os letramentos multissemióticos, ampliando a noção de letramentos a partir da linguagem dos sons, cores, imagens e o design presentes na era digital. Assim, cabe à escola, valorizar os letramentos críticos e protagonistas e relacioná-los ao trato ético dos discursos. Isso porque, não se pode tratá-los de forma instantânea, amorfa e alienada 
(PENNYCOOK, 1998). Nessa perspectiva, Rojo (2012) acrescenta que os gêneros, mídias e modalidades são muito variados. Partindo desse entendimento, a autora apresenta as concepções de multiletramento e multimodalidade. Sobre multiletramentos, (ROJO, 2012, p.19) afirma que são "textos compostos de muitas linguagens (ou modos, ou semioses) e que exigem capacidades e práticas de compreensão e produção de cada uma delas".

Para Rojo (2012), "trabalhar com multiletramentos pode ou não envolver (normalmente envolverá) o uso de novas tecnologias de informação e comunicação". Isso implica em desenvolver um trabalho na escola que parte do reconhecimento das culturas de referência dos sujeitos, ou seja, uma pedagogia que carregue em sua abordagem a diversidade cultural, os conhecimentos de mundo e a diversidade da linguagem. Destacando ainda o hibridismo que por sua vez possibilita o trabalho em diversos ambientes e plataformas (digitais ou não) facilitado pela multimodalidade e hipertextualidade. Sobre hipertexto e hipertextualidade, Xavier (2010) compreende por hipertexto "uma forma híbrida, dinâmica e flexível de linguagem que dialoga com outras interfaces semióticas, adiciona e acondiciona à sua superfície formas outras de textualidade". A multimodalidade aqui apresentada pode ser notada nos textos produzidos "sejam impressos, digitais ou analógicos (se é que ainda existem), as imagens e o arranjo de diagramação impregnam e fazem significar os textos contemporâneos" (ROJO, 2012).

Em nossa sociedade pós-moderna, permeada pelas tecnologias digitais, em se tratando da discussão sobre gêneros do discurso e letramentos, faz-se necessário provocar à compreensão de conceitos importantes para esse novo cenário, sendo assim, um deles é o conceito de letramento digital. Segundo Dudeney, Hockly e Pegrum (2016), os letramentos digitais "são habilidades individuais e sociais necessárias para interpretar, administrar, compartilhar e criar sentido eficazmente no âmbito crescente dos canais de comunicação digital".

A aprendizagem da língua escrita não acontece apenas na sala de aula, pois com as tecnologias digitais emergentes, novos espaços têm sido explorados e conquistados como lugar de produção e criação textual, mas é na escola que deve ocorrer uma organização dinâmica de objetivos práticos e autênticos favorecendo à construção do ser social leitor e produtor de gêneros discursivos diversos. Rojo (2000) considera que o ensino de língua deve preconizar os textos e os gêneros discursivos que circulam socialmente com suas especificidades como 
unidade básica de ensino, servindo de aporte para as práticas em sala de aula.

No livro a Estética da Criação Verbal (BAKHTIN, 2011), a língua é apresentada como atividade sócio-histórica, fundada nas necessidades de comunicação. Assim, a natureza da língua seria essencialmente dialógica. Para este autor, quando nos comunicamos estamos nos inserindo em práticas de uso social da linguagem, pois "Cada campo de utilização da língua elabora seus tipos relativamente estáveis de enunciados, os quais denominamos gêneros do discurso" (2011, p. 262). Para Bakhtin (2011), os gêneros do discurso são a materialização do diálogo cotidiano; portanto, sua variedade é rica e infinita. Cada esfera da atividade humana comporta um repertório de gêneros. O autor considera a grande heterogeneidade dos gêneros do discurso. Entendendo-os como correias de transmissão que levam a história à sociedade (BAKHTIN, 2011).

Como percebemos, Bakhtin (2011) apresenta caminhos para um estudo da linguagem como atividade sociointeracional. Assim, os gêneros são enfocados pelo viés dinâmico da produção discursiva. Melhor dizendo, temos a vinculação entre a utilização da linguagem e as atividades humanas. Em outros termos, Bakhtin (2011) defende que o dizer está relacionado intrinsicamente ao tipo de atividade que os falantes estão envolvidos. Os gêneros do discurso, que emergem constantemente de forma ininterrupta, estabilizam-se e evoluem no interior do comportamento e das atividades do cotidiano.

Dado o exposto, pensar práticas de letramentos e produção de gêneros do discurso em sala de aula requer, por parte dos docentes, o domínio de conhecimentos sobre a natureza e a especificidade dos gêneros produzidos em diferentes contextos de uso, das modalidades de criação e de suas plataformas. Lajolo e Zilberman (2017) na obra Literatura Infantil Brasileira: uma nova outra história, apresentam alguns questionamentos importantes quanto aos novos territórios de criação textual para crianças e jovens, com destaque para a presença do não verbal, do online, provocando-nos uma reflexão sobre esses novos espaços, além de uma concepção clara de texto, como abordaremos no próximo tópico.

\section{Concepções de texto: ponderando reflexões}

A concepção de texto não se aplica ao estudo de frases soltas e isoladas estratificadas de um contexto. Marcuschi $(2008$, p.72) afirma que "o texto é uma reconstrução do mundo, um 
mundo refratado e não apenas refletido". O referido autor discute a noção de um mundo volátil, constituído por discursos alheios onde se faz necessária a plenitude semântica proporcionando abertura para a interação discursiva fato que não poderia ocorrer em estudos de orações isoladas.

Para Koch (2015, p.17-18) “o próprio conceito de texto depende das concepções que se tenha de língua e de sujeito". Sobre isso, cita três concepções de língua: "Concepção de Língua como representação do pensamento, concepção de Língua como código e concepção de Língua interacional (dialógica)".

A concepção de língua como representação do pensamento corresponde ao sujeito psicológico individual, dono de sua vontade, suas ações e dizer, que deseja que o seu ego seja captado da maneira que foi mentalizado (KOCK, 2015). Nesta concepção não se leva em conta o foco e o interesse sobre a reflexão textual, fechando as portas para o sentido da comunicação, aproximando-se do conceito do "ouvinte" e o "entendedor", ou seja, "o processo passivo de recepção e compreensão do discurso no ouvinte" (BAKHTIN 2011, p.271), no entanto, na contramão dessa recepção, toda compreensão do discurso deve suscitar uma posição responsiva (VOLÓCHINOV, 2017).

A concepção de língua como um código, instrumento de comunicação, corresponde ao sujeito assujeitado. Nesse sentido, o indivíduo não é dono de seu discurso e de sua vontade, converte-se em sujeito anônimo social, tornando-se apenas um repetidor, um ideológico, apenas um porta voz, um sujeito inconsciente.

Na concepção de língua como código - portanto, como mero instrumento de comunicação - e de sujeito como (pré) determinado pelo sistema, o texto é visto como simples produto da codificação de um emissor a ser decodificado pelo leitor/ouvinte, bastando a este, para tanto, o conhecimento do código, já que o texto, uma vez codificado, é totalmente explícito. Também nesta concepção o papel do "decodificador, é essencialmente passivo (KOCH, 2015, p.18).

A Concepção de Língua interacional (dialógica) diferentemente das concepções anteriores, o sujeito, ao produzir seu texto, não pensa apenas nas regras da língua e em suas intenções, mas pensa também no seu leitor. Koch (2015) mostra, nessa concepção, que ao escrever, o sujeito preocupa-se com a interação, levando em conta que o leitor também faz parte 
desse processo interacional, dessa troca de conhecimentos. Mas claro, sem desconsiderar a normatividade da língua, contudo essas deixam de ser a parte mais importante do processo. Assim, "O produtor, "pensa" no que vai escrever e em seu leitor, depois escreve, lê o que escreveu, revê ou reescreve, guiado por um propósito interacional" (KOCH; ELIAS, 2012, p.34).

Antunes (2005, p.28-29) discute algumas concepções sobre o ato de escrever e, aqui, destacamos três tópicos: 1- "Escrever é, como falar, uma atividade de interação, de intercâmbio verbal; 2- escrever, na perspectiva da interação, só pode ser uma atividade cooperativa; 3escrever, a outros, e de forma interativa, é, pois, uma atividade contextualizada". Nessas concepções o de escrever está relacionado à interação, ou seja, interação como forma de agir com o outro em seus contextos sociais e históricos.

Volóchinov (2017) ignora a ruptura das práticas da linguagem desvinculadas da história dos sujeitos, mas ainda é constante a prática escolar de uma abordagem em que o ensino não preconiza a realidade viva da língua. Bakhtin (2011) também rejeita essa ruptura e afirma que não aprendemos por meio de dicionários, mas sim, a partir de enunciações concretas e para o autor,

\footnotetext{
A língua materna - sua composição vocabular e sua estrutura gramatical - não chega ao nosso conhecimento a partir de dicionários e gramáticas, mas de enunciações concretas que nós mesmos ouvimos e nós mesmos reproduzimos na comunicação discursiva viva com as pessoas que nos rodeiam. Nós assimilamos as formas da língua somente nas formas das enunciações e justamente com essas formas. As formas da língua e as formas típicas dos enunciados, isto é, os gêneros do discurso, chegam à nossa experiência e à nossa consciência em conjunto e estreitamente vinculadas. Aprender a falar significa aprender a construir enunciados (porque falamos por enunciados e não por orações isoladas e, evidentemente, não por palavras isoladas) (BAKHTIN, 2011, p.283).
}

Volóchinov (2017, p.233) afirma que "todos os conteúdos objetivos existem na fala viva, são ditos ou escritos com relação à certa ênfase valorativa". Compreendemos então os inúmeros relatos de alunos e alunas, quando em uma determinada aula de escrita textual em língua portuguesa, desprovida de contextos concretos, indagam sobre a aplicação prática do que se está sendo ensinado tal como questionam: "o que faço e como aplico isso em minha vida? Qual seu valor prático? ". Possenti, ao pensar práticas de língua portuguesa na escola defende: 
O modo de conseguir na escola a eficácia obtida nas casas e nas ruas é "imitar" da forma mais próxima possível às atividades linguísticas da vida. Na vida, na rua, nas casas, o que se faz é falar e ouvir. Mas, dado o projeto da escola, ler e escrever são atividades importantes. Como aprenderemos a falar? Falando e ouvindo. Como aprenderemos a escrever? Escrevendo e lendo, sendo corrigidos, e reescrevendo, e tendo nossos textos lidos e comentados muitas vezes, com uma frequência semelhante à frequência da fala e das correções da fala (POSSENTI, 1996, p.48).

No âmbito escolar, se observarmos realmente além da superfície dos textos, iremos perceber os inúmeros contextos envoltos, as inúmeras vozes que assumem claramente uma posição. Nesse sentido, "quando o enunciado assume um caráter pleno, além da unidade da língua, teremos prontamente uma ativa posição responsiva do falante" (BAKHTIN, 2011, p.287).

Como então conceber e aceitar um texto sem contexto social? Para Bakhtin (2011, p.401) isso seria impossível já que "um texto só tem vida contatando com outro texto (o contexto)". Para o autor, "só no ponto desse contato de textos eclode a luz que ilumina retrospectiva e prospectivamente, iniciando dado texto no diálogo" (p. 401). O que interessa no diálogo para o círculo de Bakhtin são os embates ideológicos (VOLÓCHINOV, 2017, p.233). E em outras palavras, o que interessa é a "faísca elétrica surgida apenas durante o contato de dois polos opostos (p.233)" o círculo de Bakhtin volta o seu olhar para um diálogo direto e vivo.

\section{Contexto metodológico}

A investigação que apresentamos trata-se de uma observação de cunho qualitativo, do tipo pesquisa-ação (THIOLLENT, 2011). Segundo Thiollent (2011), é um tipo de pesquisa social, realizada através de uma ação na qual os pesquisadores e os participantes representativos do evento em foco estão envolvidos de modo cooperativo ou participativo.

A pesquisa se deu em uma escola pública estadual da cidade de Maceió-Alagoas. Na ocasião, realizamos oficinas de produção de textos e práticas de leitura. Para o planejamento das oficinas utilizamos como suporte o livro didático de língua portuguesa (BORGATTO, 2015), do Programa Nacional do Livro e do Material Didático (PNLD) para o triênio (2017-2019).

No que diz respeito à intervenção em sala de aula, optamos por trabalhar gêneros do discurso (BAKHTIN, 2011), da esfera publicitária. Nosso intuito voltava-se ao desejo de 
ultrapassar a linguística estrita e focar nas abordagens de realidades sócio-históricas. Portanto, condicionando a produção de texto ao seu contexto vivo.

As referidas oficinas ocorreram em quatro aulas, de 50 minutos cada, ministradas em dois dias. Metodologicamente levantamos questões sobre o gênero proposto (publicitário) e, para este fim, usamos jornais e revistas. Durante as aulas, projetamos vídeos, apresentamos propagandas publicitárias de grandes marcas utilizando como recurso a TV, disponível na escola, para que os alunos visualizassem e compreendessem a estrutura organizacional de uma propaganda.

Assim, na primeira aula, alguns elementos fundamentais para organização do texto publicitário foram apresentados aos alunos, a fim de que compreendessem o uso dos diversos recursos de linguagem que foram escolhidos estrategicamente para convencer, a exemplo os elementos da "marca":

$\checkmark$ Símbolo - Imagem ou elemento que identifica a marca;

$\checkmark$ Logotipo - Grupo de letras que forma sigla ou palavra para representar a marca;

$\checkmark$ Slogan - frase curta para que seja associada à marca.

Nas aulas seguintes (segunda e terceira), propusemos um trabalho em sala de aula para que os alunos pudessem, de forma autônoma, criar e recriar quantas vezes fosse necessário o texto publicitário para si e para o seu outro (BAKHTIN, 2011).

Nas orientações didáticas para a produção do gênero publicitário, sinalizamos que os alunos poderiam fantasiar dando "asas" à criatividade. Para elaboração dos textos, os discentes seguiriam as seguintes informações: 1 - Escolha um produto que goste; 2- Imagine que precisa convencer um colega de comprar ou usar o seu produto; 3- Defina o público para o qual quer vender seu produto; 4- Se precisar, refaça o seu texto quantas vezes for necessário até chegar a uma ideia que te traga confiança; 5- Se criar imagens e pinturas, relacione-as ao texto escrito; 6 Apresente as qualidades do produto; 7- Convide o leitor a comprar com palavras impositivas e emotivas.

Como apoio, de forma estratégica, criamos um contexto no qual os educandos foram orientados a pesquisar em seus celulares exemplares de textos publicitários, observando mais uma vez suas estruturas e modelo organizacional. Após a pesquisa (prática de letramento), proporcionamos aos alunos a socialização dos achados no acontecimento da aula (GERALDI, 2015). 
Na quarta aula, os alunos foram convidados a darem continuidade à construção do gênero discursivo escolhido, de modo que, entre outros aspectos, focassem na função discursiva do referido gênero, a persuasão, "pois falar é uma forma de ação sobre o outro [...]. Toda enunciação constitui um ato que visa modificar uma situação[...] visa produzir uma modificação nos destinatários" (MAINGUENEAU, 2005, p.53).

No mundo de grande competição, tentar influenciar a opinião do outro é uma prática constante. A intenção de persuadir está presente em muitas e diferentes formas de discursos, mesmo que de uma maneira não tão aparente. Nesse sentido, como estratégia de convencimento, deve ser levada em conta a escolha das palavras e a organização visual do texto.

No contexto do dia a dia, na ocasião da intervenção didática, na sala de aula, tínhamos cerca de 12 alunos, mas por muitos motivos pessoais, podíamos contar com a permanência e assiduidade de apenas 8. Dentre os textos produzidos nas oficinas com o gênero publicidade, selecionamos 4 para a discussão que teceremos adiante. Consideramos nos referidos textos os elementos constitutivos do gênero publicitário tendo por foco a produção textual em contextos de significações sociais.

\section{Análise e discussão dos dados}

Pensar em práticas de linguagens é pensar em sujeitos inseridos em um mundo vivo, ou seja, leitura e escrita na vida. Essas práticas perpassam o simples movimento de alfabetizar: "é trabalhar com letramentos múltiplos, com as múltiplas leituras" (ROJO, 2009, p.118), no intuito de gerar efeitos de compreensão e resposta em diferentes contextos de forma proficiente e de consciência plena. No primeiro texto que iremos analisar percebemos três aspectos que nos chamam a atenção: $1^{\circ}$ - significação entre texto e contexto; $2^{\circ}$ - O uso do vocativo; 30 intertextualidade e conhecimento de mundo ao usar o termo " $50 \%$ off. " 


\section{HSE HORIZON TES}

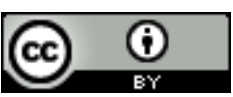

Figura 1 - Texto publicitário do aluno João ${ }^{5}$

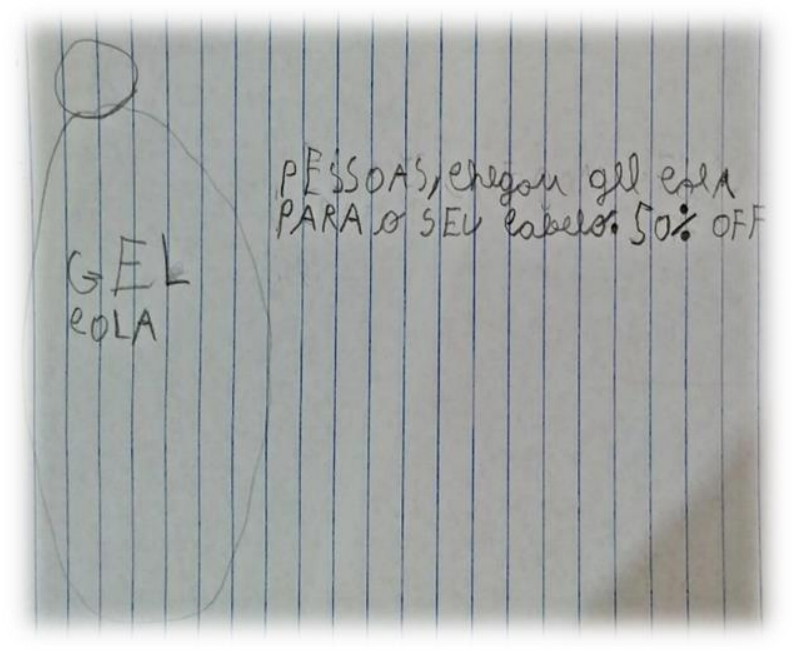

Fonte: produção de aluno - pesquisa PIBID

Quadro 1. Transcrição da figura 1

"Pessoas, chegou gel cola para o seu cabelo. $50 \%$ off"

Fonte: elaborado pelos autores

No que se refere ao primeiro aspecto, descobrimos através do discurso do aluno João que sua mãe é vendedora de cosméticos desde que ele nasceu. Ao nos entregar o texto, o discente fez questão de dizer: "Eu criei uma propaganda para minha mãe que vende Avon". Ele foi criado apenas com a mãe e a venda de produtos de beleza lhe traz significação. Pois, segundo ele, esse era o único meio pelo qual sua mãe sustenta a casa.

A consideração da avaliação social é necessária justamente para compreender a formação histórica do tema e das significações que o realizam. A formação do sentido da língua está sempre relacionada com a formação do horizonte valorativo do grupo social, e, por sua vez, essa formação, compreendida como um conjunto de tudo que possui significação ou importância para o grupo, é determinada inteiramente pela ampliação da base econômica (VOLÓCHINOV, 2017, p.237-238).

Quanto ao segundo aspecto, o aluno João cursava o $8^{\circ}$ ano e, provavelmente, já havia

\footnotetext{
${ }^{5}$ Para preservar a identidade dos sujeitos que participaram da pesquisa, utilizaremos nomes fictícios para os alunos participantes da pesquisa.
}

Periódico Horizontes - USF - Itatiba, SP - Brasil - e020006 
estudado sobre "vocativo". Em conversa com ele, foi-Ihe questionado como chegou à conclusão de colocar vírgula após a palavra "pessoas". No contexto, ele respondeu: "Estou querendo chamar a atenção do freguês, por isso resolvi separar (isolar) a palavra". Em nenhum momento o aluno se referiu ao uso do vocativo, mas entende-se perfeitamente o que ele quis dizer. Isso porque "a função do vocativo é invocar, chamar ou nomear, com ênfase maior ou menor, uma pessoa ou coisa personificada" (CELSO CUNHA; LINDLEY CINTRA, 2013, p.174).

No que diz respeito ao terceiro aspecto, a leitura do texto evidencia que ele conseguiu de forma significativa apresentar seus conhecimentos de mundo e a intertextualidade revelando a presença de um texto para outro através de citação ou alusão quando cita o termo " $50 \%$ off". Sabemos que por traz desse termo habita um mundo de vozes com inúmeros discursos situados e entrelaçados entre si para um determinado fim específico.

Isso significa que todo texto é um objeto heterogêneo, que revela uma relação radical de seu interior com seu exterior; e, desse interior, evidentemente, fazem parte outros textos que the dão origem, que o predeterminam, com os quais dialoga, que retoma, a que alude, ou a que se opõe (KOCH, 2018, p.59).

Para Marcuschi (2008) não existe texto que não mantenha aspecto intertextual, nenhum texto se acha isolado e solitário. Correferimos a intertextualidade no texto do aluno João ao citar "50\% off", ao que relata Bakhtin (2011, p.300), "o falante não é um Adão Bíblico, só relacionado a objetos não nomeados, aos quais dá nome pela primeira vez, portanto, não seremos os primeiros a falar a palavra pela primeira vez, tomamos as palavras do mundo em que vivemos". Ratificamos o que Rojo (2012) expõe quando discorre sobre a pedagogia dos multiletramentos, a autora define como sendo uma cultura "sensível" a cultura dos sujeitos e que também reconhece o conhecimento de mundo que cada indivíduo carrega em si, das suas vivências e experiências. O texto publicitário na sociedade pós-moderna é carregado de signos, sentidos e significados, apela para o uso do som, das imagens, das cores e de uma linguagem multimodal, buscando alcançar os seus alvos. Podemos experenciar essas afirmativas quando lemos os anúncios em impressos, bem como em aplicativos que utilizam a web como meio de veiculação, sobretudo aplicativos em smartphones que utilizam tecnologia mobile.

O texto do quadro 1 desvela-nos que as vivências de mundo são ressignificadas nas práticas de letramento em sala, quando os sujeitos se apropriam desse conhecimento e passam 


\section{USF HORIZONTES}

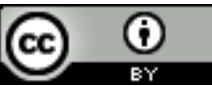

DOI: https://doi.org/10.24933/horizontes.v38i1.846

a utilizá-los nas suas práticas sociais. Esse novo cenário da chamada cultura digital (LEVY, 1999) permite aos sujeitos uma maior exploração das suas competências, sobretudo, competências ligadas à criatividade, liberdade e capacidade de criação.

Na continuidade da análise, observe as figuras seguintes:

Figura 2- Texto publicitário da aluna Fernanda

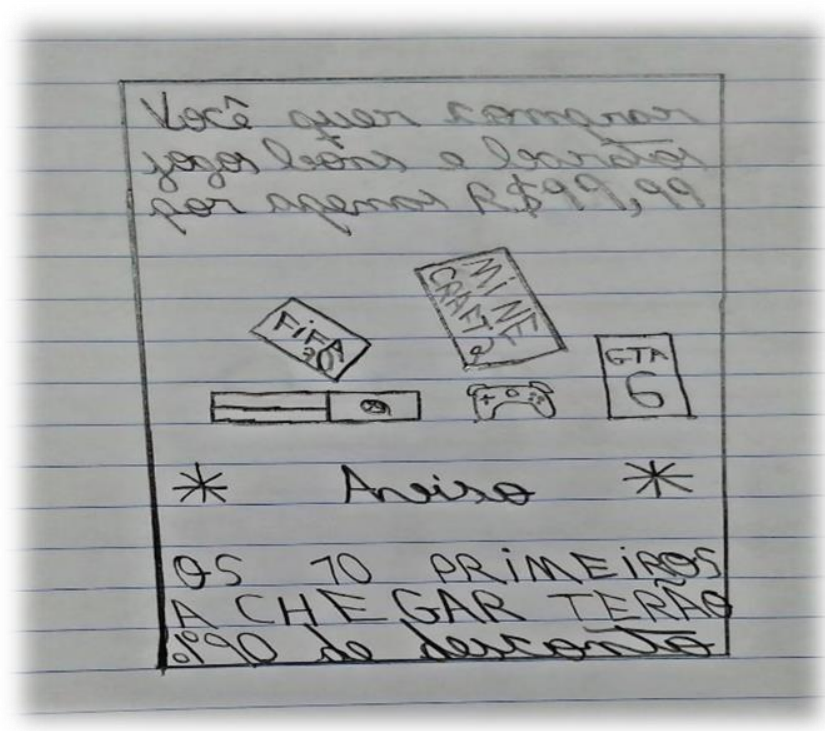

Fonte: produção de aluno - pesquisa PIBID

Figura 3- Texto publicitário da aluna Juliana

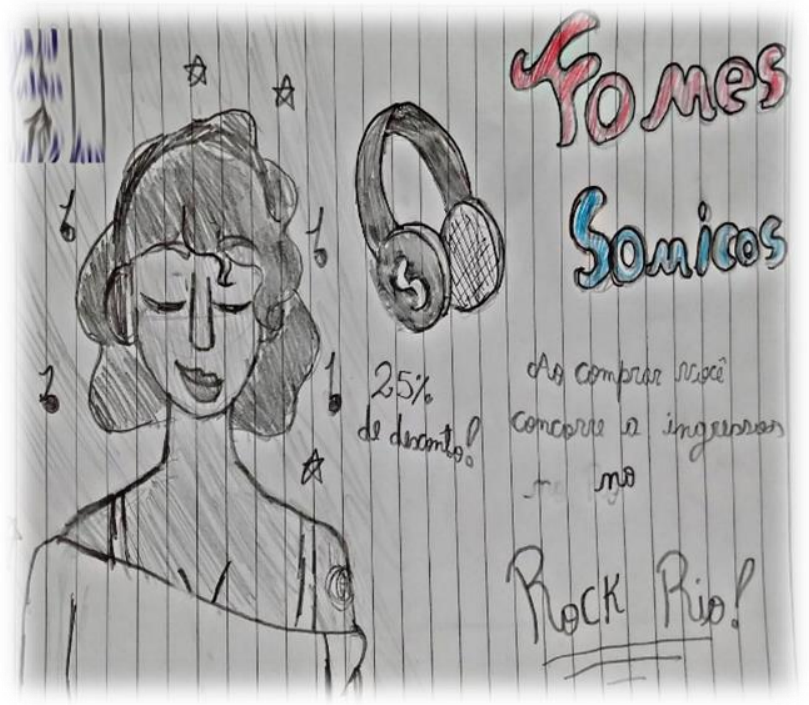

Fonte: produção de aluno - pesquisa PIBID

Figura 4- Texto publicitário do aluno Pedro 


\section{HSE HORIZON TES}
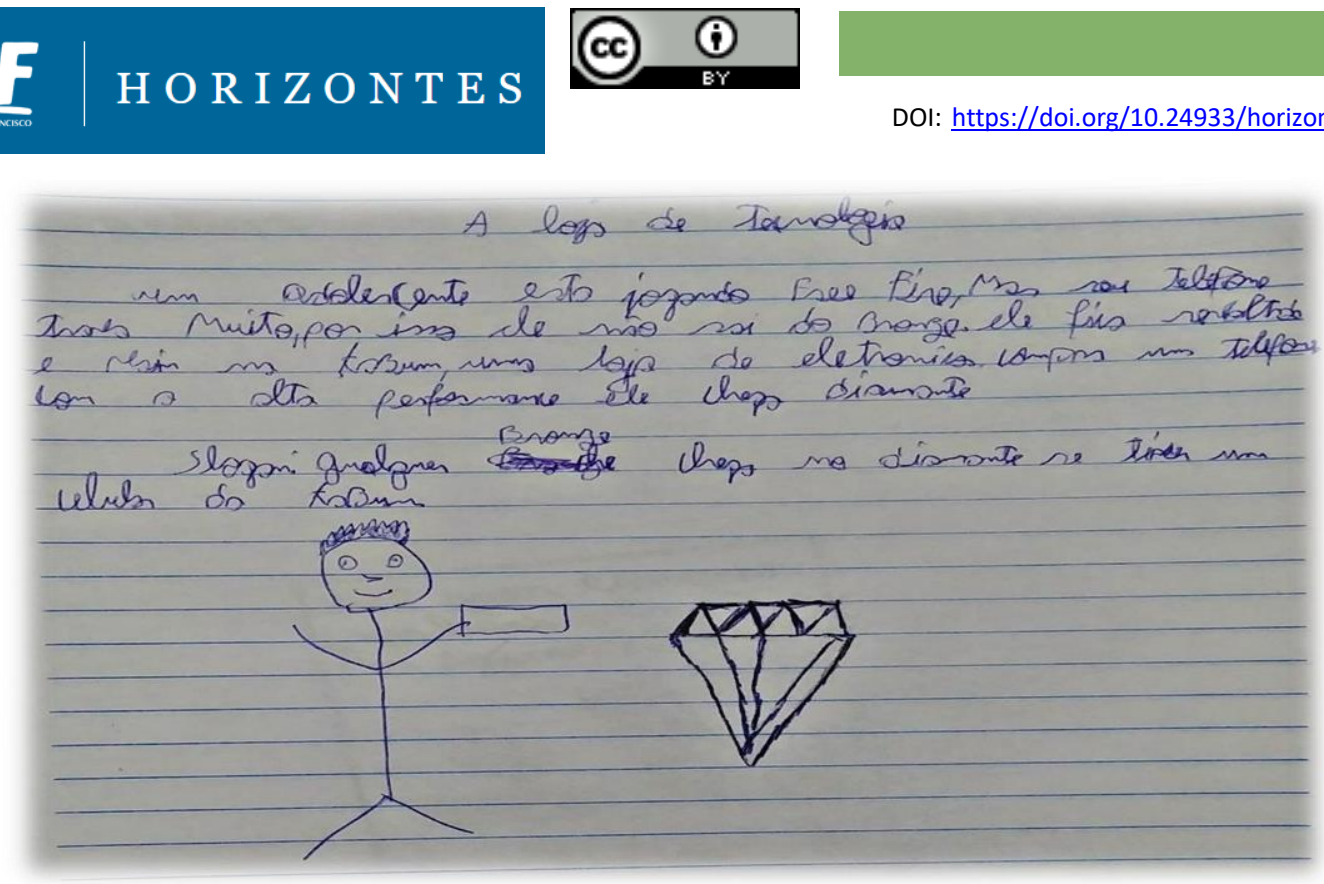

Fonte: produção de aluno - pesquisa PIBID

Seguindo nossa análise, chamamos a atenção para um ponto de convergência entre os textos produzidos pelos alunos Fernanda, Juliana e Pedro. O discurso em pauta é sobre jogos e relacionado à tecnologia. Essa observação nos leva a reflexão de que os sujeitos nativos digitais estão cada vez mais envolvidos com as tecnologias digitais da informação e comunicação (TDIC). De acordo com Prensky (2001), pode-se designar como nativo digital o sujeito que nasceu na era digital e é capaz de realizar múltiplas atividades em ambientes que envolvam tecnologias digitais, demonstrando destreza e confiança no uso das TDIC e da internet. As produções das figuras 2, 3 e 4 demonstram que há uma preferência desse público (crianças e adolescentes) em utilizar as tecnologias emergentes no seu dia-a-dia, ou seja, estão cada vez mais conectados e utilizando esses letramentos digitais no cotidiano, nas suas práticas sociais.

A escolha temática nos anúncios não se repetiu apenas nos textos que escolhemos para exposição aqui nesta investigação, mas aconteceu de forma quase que generalizada por parte dos 8 (oito) alunos presentes nas atividades de produção do gênero. Observe as transcrições retiradas dos textos acima: 
"Você quer comprar jogos bons e baratos por apenas R\$ 99,99. FIFA 30, MINE CRAFTA 2, GTA 6. Aviso, os primeiros a chegar terão $90 \%$ de desconto. "

Fonte: elaborado pelos autores

Quadro 3. Transcrição da figura 3

"Fones sonicos $25 \%$ de desconto! Ao comprar você concorre a ingressos no Rock Rio!"

Fonte: elaborado pelos autores

Quadro 4. Transcrição da figura 4

"A loja de tecnologia um adolescente está jogando free fire, mas seu telefone trava muito, por isso ele não sai do bronze. Ele fica revoltado e também e vai na Tabum, uma loja de eletrônicos comprar um telefone com a alta performance ele chega a diamante. Jogar qualquer bronze chega no diamante se tiver um celular da tabum."

Fonte: elaborado pelos autores

Para tentar elucidar essa convergência de discursos, buscamos entender em Vygotsky (2007), que todo aprendizado começa muito antes da ida dos sujeitos à escola. Sendo assim, as vozes sociais tomam e constituem os discursos, por essa razão, notamos mais uma vez questões de significação nos discursos produzidos. O fato do ser humano se destacar de todos os outros seres vivos em diversos aspectos e um deles é a percepção de objetos reais, ou seja, a percepção do que lhe é concreto e do que Ihe traz sentido. Conseguimos de forma singular perceber o mundo não apenas em cores e formas como fazem os animais, mas "observamos um mundo de sentidos e significados" (VIGOTSKY, 2007, p.24).

Aspectos peculiares e convergentes com o texto do aluno João, a saber: intertextualidade e conhecimento de mundo se fazem presentes nos últimos três textos. Verificamos frases como: "Fifa 30", "90\% de desconto", 25\% de desconto, "Rock Rio" e "free fire". Com estas citações inferimos que os sujeitos se expressam a partir daquilo que thes é familiar, significativo, daquilo que vivenciam, daquilo que Ihes trazem valor e sabemos que "sem ênfase valorativa não há palavra" (VOLÓCHINOV, 2017, p.233).

Na Figura 4, podemos observar que o aluno Pedro empregou de forma adequada a conjunção adversativa ao dizer: "mas seu telefone trava muito". "Toda forma gramatical é, ao 
mesmo tempo, um meio de representação. Por isso, todas essas formas podem e devem ser analisadas do ponto de vista das suas possibilidades de representação e de expressão" (BAKHTIN, 2013, p. 25). "As formas gramaticais não podem ser estudadas sem que se leve sempre em conta seu significado estilístico". (BAKHTIN, 2013, p.23). O autor diz que na prática, muito raramente se aborda em sala de aula as explicações estilísticas para as formas da gramática. Existe a necessidade premente de levar ao aluno o conhecimento prático das relações entre escrita e prática social. Para Bakhtin (2013), o estudo da sintaxe sem uma abordagem estilística não enriquece a linguagem e priva todo o significado criativo, neste caso, teríamos apenas o estudo de uma linguagem criada, pronta e finalizada.

Em conversas posteriores com os alunos os relatos eram de que sabiam usar os termos de "forma cega", ou seja, usavam a conjunção sem saber o seu devido valor de significação e seus efeitos de sentidos em suas próprias produções textuais. Por isso, vale novamente assinalar que é de extrema importância um trabalho em sala de aula que levem os sujeitos a atividades que lhes tragam sentidos práticos e extrapolem o ensino abstrato da língua.

\section{Considerações finais}

Ao longo de todo este trabalho buscamos marcar as relações entre os sujeitos e o mundo através do uso real da língua em situações que signifiquem o concreto. Não interpretamos e vemos o mundo por meio de análises linguísticas abstratas. Na investigação dos textos dos alunos ficou evidente que quando escrevemos ou falamos estamos discursando a partir de nossa própria realidade, falamos do que existe, falamos do que experimentamos, falamos do que queremos experimentar.

$\mathrm{Na}$ análise do trabalho pudemos observar que texto e significação estão entrelaçados e não podem obter uma concretude de forma separada. Isto é, as relações de mundo predominam de modo que pode ser trabalhado de forma enfática como prática dos multiletramentos possibilitando a cada sujeito práticas de escrita e leitura de forma ética, crítica e democrática.

Ao trabalhar o texto publicitário, nesse artigo, não nos limitamos a visualizar apenas as formas de construções do texto e suas estruturas formais. Pois, esta é apenas a parte de um grande contexto de significados discursivos que envolvem as questões de gêneros discursivos, 


\section{HSF}

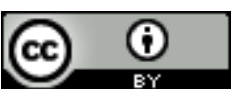

BY

intertextualidade, inúmeras vozes, escutas, sons, tonalidades e cores, que se movem na história.

Enfatizamos a relevância de estudos interligados a contextos próprios dos sujeitos, um texto só pode assumir a relevância do sentido pleno a partir de seu contexto real, é impossível haver aprendizado por meio de enunciados neutros. Fica mais fácil compreender a convergência dos discursos dos alunos em seus textos quando voltamos nosso olhar para a sua inserção social. Refletindo não de forma individual, mas de forma a saber que, em nossos dias, estamos mergulhados em um mundo semiótico, capitalista e permeado pelas tecnologias digitais da informação e comunicação, permitindo-nos explorar as competências de multiletramentos em múltiplas interfaces e práticas sociais.

\section{Referências}

ANTUNES, I. Lutar com palavras: Coesão e Coerência. 1 ed. São Paulo: Parábola Editorial, 2005.

BAKHTIN, M. Estética da Criação Verbal. Os Gêneros do Discurso. 6 ed. São Paulo: WMF Martins Fontes, 2011.

BAKHTIN, M. Questões de estilística no ensino da língua. 1 ed. São Paulo: Editora 34, 2013.

BORgATtO, A. M. T.; BERTIN, T.; MARCHEZI, V. Projeto Teláris Português: Ensino Fundamental 2. 2 ed. São Paulo: Ática, 2015.

CUNHA, C.; CINTRA, L. Gramática do Português Contemporâneo. 6 ed. Rio de Janeiro: Lexikon, 2013.

DUDENEY, G; HOCKLY, N; PEGRUM, M. Letramentos digitais. 1 ed. Tradução de Marcos Marcionilo. Inserir edição São Paulo: Parábola Editorial, 2016.

FREIRE, P. A Importância do Ato de Ler. 23 ed. Cortez, São Paulo, 1989.

GERALDI, J.W. A Aula como Acontecimento. 2 ed. São Paulo: Pedro \& João Editores, 2015.

KOCH, I. G. V. Desvendando os Segredos do Texto. 8 ed. Editora Cortez. São Paulo, 2015.

KOCH, I. G. V. O Texto e a Construção dos Sentidos. 10 ed. São Paulo: Editora Contexto, 2018.

KOCH, I. G. V.; ELIAS, V. M. Ler e Escrever. Estratégias de Produção Textual. 1 ed. São Paulo: Editora Contexto, 2012.

Periódico Horizontes - USF - Itatiba, SP - Brasil - e020006 
LAJOLO, M.; ZILBERMAN, R. Literatura infantil brasileira: uma nova/outra história. 1 ed. Inserir edição. Curitiba: PUCPRess, 2017.

LÉVY, P. Cibercultura. 1 ed. Inserir edição. São Paulo: Editora 34, 1999.

LOPES, Moita. Uma linguística aplicada mestiça e ideológica: interrogando o campo como linguista aplicado. In: Por uma linguística aplicada indisciplinar/ Branca Fabrício [et al]. 1 ed. São Paulo: Parábola Editorial, 2006.

MAINGUENAU, D. Análise de Textos de Comunicação. 4 ed. Tradução de Cecília P. de Souza, Décio Rocha. São Paulo: Cortez, 2005.

MANACORDA, M. Marx e a pedagogia moderna. 1 ed. Campinas: Alínea, 2007.

MARCUSCHI, L. A. Produção Textual, Análise de Gêneros e Compreensão. 1 ed. São Paulo: Parábola Editorial, 2008.

PENNYCOOK, Alastair. A linguística Aplicada dos anos 90: em defesa de uma abordagem crítica. In: SIGNORINI, I.; CAVALCVANTI, M.C. (orgs.) Linguística Aplicada e Transdiciplinaridade. 2 ed. Campinas: Mercado de Letras, 1998.

POSSENTI, S. Por que (não) Ensinar Gramática na Escola. 1 ed. Campinas: Mercado das Letras: Associação de Leitura do Brasil, 1996.

PRENSKY, M. Digital natives, digital immigrants. 2001. Disponível em: http://migre.me/tY2Km. Acesso em 22 de dez. 2017.

ROJO, R. H. R (org.). A Prática de Linguagem em Sala de Aula: Praticando os PCNs. 1 ed. São Paulo: EDUC Campinas: Mercado de Letras, 2000.

ROJO, R. H. R Letramentos Múltiplos, escola e inclusão social. 1 ed . São Paulo: Parábola Editorial, 2009.

ROJO, R. H. R. Pedagogia dos multiletramentos: diversidade cultural e de linguagens na escola. In: ROJO, R. H. R; MOURA, E. (orgs). Multiletramentos na escola. 1 ed. São Paulo: Parábola Editorial, 2012. p. 11-31.

STREET, B. V. Cross-Cultural Approaches to Literacy. 1 ed. New York: Cambridge University Press, 1993.

THIOLLENT, Michel. Metodologia da Pesquisa-Ação. 18 ed. São Paulo: Editora Cortez, 2011.

VOLÓCHINOV, V. Marxismo e Filosofia da Linguagem. Problemas Fundamentais do Método Sociológico na Ciência da Linguagem. 1 ed. São Paulo: Editora 34, 2017. 
VIGOTSKY, L. S. A Formação Social da Mente. 7 ed. São Paulo: Editora Martins Fontes, 2007.

XAVIER, A. C. Leitura, texto e hipertexto. In: MARCUSCHI, L. A.; XAVIER, A. C (orgs). Hipertexto e gêneros digitais: novas formas de construção de sentido. 3 ed. São Paulo: Cortez, 2010.

\section{AGRADECIMENTOS}

À Fundação de Amparo à Pesquisa do Estado de Alagoas (FAPEAL) pelo apoio financeiro para o desenvolvimento deste estudo.

Recebido em agosto de 2019.

Aprovado em dezembro de 2019. 